Notre Dame Journal of Formal Logic

Volume 26, Number 4, October 1985

\title{
Investigations in Protothetic
}

\author{
AUDOËNUS LE BLANC
}

In this article I present some results of five years' research into Leśniewski’s protothetic. ${ }^{1}$ I outline deductions from the axiom $A_{n}$ considerably shorter than those previously known (see [9]) and I derive the laws of implication from this axiom without using the rule of extensionality. ${ }^{2}$ Since this paper can best be read in the light of articles by Professor Sobociński published in this Journal (see [8], [9], and [10]), I have largely adopted his conventions of symbolism, and the following symbols in particular:

$\alpha$ The rule permitting definitions of new constants (see [8], pp. 58-59).

$\beta$ The rule for distributing quantifiers (see [8], p. 59).

0 An informal abbreviation for ' $[u] . u$ '.

1 An informal abbreviation for ' $[u] . u . \equiv .[u] . u$ '.

From the axiom

$$
A_{n}[p q]:: p \equiv q . \equiv[f] \therefore f(p f(p 0)) . \equiv:[r]: f(q r) . \equiv . q \equiv p
$$

we prove the following theorems:

D1 $[p] . p \equiv \operatorname{As}(p)$

L1 $[f p] \therefore f(p f(p 0)) . \equiv:[r]: f(\operatorname{As}(p) r) . \equiv . \operatorname{As}(p) \equiv p$

D2 $[p r] \therefore p \equiv r . \equiv . \operatorname{As}(p \equiv r): \equiv \operatorname{Vr}(p r)$

L2 $[p r] . \operatorname{Vr}(p r)$ $\left[A_{n} q / \operatorname{As}(p) ; \mathrm{D} 1\right]$

$\mathbf{L 3}[p r]: \operatorname{Vr}(\operatorname{As}(p) r) . \equiv . \operatorname{As}(p) \equiv p$

[D2; D1 $p / p \equiv r]$

We can now establish the following four metarules of procedure:

S I (see [9], pp. 114-115) If we have in the system a thesis of the type

$$
[x, y, \ldots]: A . \equiv . B
$$

(with or without an initial quantifier), then we can add the corresponding thesis 

a) $\quad[x, y, \ldots]: B=A$
[The assumption]
b) $\quad\left[x^{\prime}, y^{\prime}, \ldots\right): A^{\prime} . \equiv . B^{\prime}$
[Substitution of $\mathfrak{a}$ to eliminate any free variables of shapes ' $f$ ' or ' $r$ '.]
c) $\left[f, x^{\prime}, y^{\prime}, \ldots\right]:: f\left(A^{\prime} f\left(A^{\prime} 0\right)\right) \equiv \therefore[r] \therefore f\left(B^{\prime} r\right) . \equiv: B^{\prime} . \equiv A^{\prime}$
๖) $\quad\left[r, x^{\prime}, y^{\prime}, \ldots\right] \therefore \operatorname{Vr}\left(B^{\prime} r\right) \equiv . B^{\prime} . \equiv . A^{\prime}$

$$
\left[A_{n} p / A^{\prime}, q / B^{\prime} ; \mathfrak{b}\right]
$$
e) $\quad\left[x^{\prime}, y^{\prime}, \ldots\right]: B^{\prime} . \equiv . A^{\prime}$
f) $[x, y, \ldots]: B . \equiv . A$
[c $\left.f / \mathrm{Vr} ; \mathrm{L} 2 p / A^{\prime}, r / \operatorname{Vr}\left(A^{\prime} 0\right)\right]$
$\left[\delta ; \mathrm{L} 2 p / B^{\prime}\right]$
[Substitution of $e$ to restore the original variables]

S II If we have in the system two corresponding theses of types

$$
\begin{aligned}
& {[x, y, \ldots]: A . \equiv . B} \\
& {[x, y, \ldots] \cdot B,}
\end{aligned}
$$

then we can add the corresponding thesis

$$
[x, y, \ldots] . A \text {. }
$$

This follows immediately from metarule S I.

S III If we have in the system two corresponding theses of types

$$
\begin{aligned}
& {[x, y, \ldots]: A \equiv . B} \\
& {[x, y, \ldots] \cdot F(A)}
\end{aligned}
$$

(where ' $F(A)$ ' represents any meaningful expression which contains at least one expression equiform with ' $A$ ' not falling within the scope of any internal quantifier), then we can add the corresponding thesis

$$
[x, y, \ldots] . F(B) \text {. }
$$

a) $[x, y, \ldots]: A \equiv . B$

[Assumption]

b) $\quad[x, y, \ldots] \cdot F(A)$

[Assumption]

c) $\quad\left[x^{\prime}, y^{\prime}, \ldots\right]: A^{\prime} \equiv . B^{\prime}$

[These substitutions of $\mathfrak{a}$ and $\mathfrak{b}$

b) $\left[x^{\prime}, y^{\prime}, \ldots\right] \cdot F^{\prime}\left(A^{\prime}\right)$ eliminate any free variables of shapes ' $f$ ', ' $p$ ', ' $q$ ', or ' $r$ '.]

e) $\quad\left[x^{\prime}, y^{\prime}, \ldots\right]: B^{\prime} \equiv . A^{\prime}$

[S I: c]

f) $\quad\left[x^{\prime}, y^{\prime}, \ldots\right] \cdot \mathrm{As}\left(F^{\prime}\left(A^{\prime}\right)\right)$

[D1 $p / F^{\prime}\left(A^{\prime}\right) ;$ b]

g) $\left[f, x^{\prime}, y^{\prime}, \ldots\right]:: f\left(A^{\prime} f\left(A^{\prime} 0\right)\right) . \equiv[r] \therefore f\left(B^{\prime} r\right) . \equiv: B^{\prime} . \equiv . A^{\prime}$

$$
\left[A_{n} p / A^{\prime}, q / B^{\prime} ; \mathrm{c}\right]
$$

h) $\left[p, q, r, x^{\prime}, y^{\prime}, \ldots\right]:: \operatorname{Vr}\left(\operatorname{As}\left(F^{\prime}(p)\right) r\right) . \equiv: \operatorname{As}\left(F^{\prime}(p)\right) . \equiv . F^{\prime}(q)$ $\therefore \equiv . G\left(p x^{\prime} y^{\prime} \ldots\right)(q r)$

i) $\quad\left[x^{\prime}, y^{\prime}, \ldots\right] . G\left(A^{\prime} x^{\prime} y^{\prime} \ldots\right)\left(A^{\prime} G\left(A^{\prime} x^{\prime} y^{\prime} \ldots\right)\left(A^{\prime} 0\right)\right)$

f) $\quad\left[r, x^{\prime}, y^{\prime}, \ldots\right] \therefore G\left(A^{\prime} x^{\prime} y^{\prime} \ldots\right)\left(B^{\prime} r\right) . \equiv: B^{\prime} . \equiv . A^{\prime}$

[g $\left.f / G\left(A^{\prime} x^{\prime} y^{\prime} \ldots\right) ; \mathrm{i}\right]$

1)

$\left[r, x^{\prime}, y^{\prime}, \ldots\right] . G\left(A^{\prime} x^{\prime} y^{\prime} \ldots \nsucc\left(B^{\prime} r\right)\right.$

[S II: $\mathfrak{f} ; \mathrm{e}]$ 
m) $\left[r, x^{\prime}, y^{\prime}, \ldots\right] \therefore \operatorname{Vr}\left(\operatorname{As}\left(F^{\prime}\left(A^{\prime}\right)\right) r\right) . \equiv: \operatorname{As}\left(F^{\prime}\left(A^{\prime}\right)\right) . \equiv F^{\prime}\left(B^{\prime}\right)$

n) $\quad\left[x^{\prime}, y^{\prime}, \ldots\right] \cdot F^{\prime}\left(B^{\prime}\right)$

[S II: h $\left.p / A^{\prime}, q / B^{\prime} ; \mathfrak{l}\right]$

o) $\quad[x, y, \ldots] \cdot F(B)$ [m; L2 $p / \operatorname{As}\left(F^{\prime}\left(A^{\prime}\right)\right) ; \mathfrak{f l}$ [Substitution of $\mathfrak{n}$ to restore the original variables]

S IV If we have in the system corresponding theses of types

$[x, y, \ldots]: A . \equiv . B$

$[x, y, \ldots] . F(B)$

(with ' $F(B)$ ' understood as in $S I I I$ ), then we can add the corresponding thesis $[x, y, \ldots] . F(A)$.

This follows immediately from S I and S III.

Aided by these rules, we prove the following theses:

\begin{tabular}{|c|c|c|}
\hline L4 & {$[p r]: \operatorname{Vr}(p r) . \equiv . p \equiv p$} & [S IV: D1; L3] \\
\hline $\mathbf{L 5}$ & {$[p] \cdot p \equiv p$} & {$[\mathrm{~L} 4 ; \mathrm{L} 2]$} \\
\hline $\mathbf{L 6}$ & {$[f p] \therefore f(p f(p 0)) . \equiv:[r]: f(p r) . \equiv . p \equiv p$} & {$\left[A_{n} q / p ; \mathrm{L} 5\right]$} \\
\hline D3 & {$[p q] \therefore q . \equiv q \equiv p: \equiv F b(p q)$} & {$[\alpha]$} \\
\hline D4 & {$[p r]: F b(\operatorname{Vr}(0 r) p) \equiv \operatorname{Vr}_{1}(p r)$} & {$[\alpha]$} \\
\hline L7 & {$[r]: F b(10) . \equiv \operatorname{Vr}_{1}(0 r)$} & [S III: L4 $p / 0 ; \mathrm{D} 4 p / 0]$ \\
\hline $\mathbf{L 8}$ & {$[r] \therefore F b(10) . \equiv .1: \equiv: \operatorname{Vr}_{1}(0 r) . \equiv .1$} & $\begin{array}{r}\text { [S III: L7; } \\
\text { L5 } p / F b(10) \equiv .1]\end{array}$ \\
\hline 9 & $F b(10) . \equiv .1: \equiv:[r]: \operatorname{Vr}_{1}(0 r) . \equiv .1$ & {$[\mathrm{~L} 8 ; \beta]$} \\
\hline $\mathbf{L 1 0}$ & $\operatorname{Vr}_{1}\left(0 \operatorname{Vr}_{1}(00)\right) . \equiv: F b(10) . \equiv .1$ & IV: L9; L6 $\left.f / \mathrm{Vf}_{1}, p / 0\right]$ \\
\hline L11 & $F b(10) . \equiv: F b(10) . \equiv .1$ & S IV: L7 $\left.r / \mathrm{Vr}_{1}(00) ; \mathrm{L} 10\right]$ \\
\hline $\mathbf{L 1 2}$ & $F b(1 F b(10))$ & D3 $q / F b(10), p / 1 ;$ L11] \\
\hline $\mathbf{L 1 3}$ & {$[r]: F b(1 r) . \equiv .1 \equiv 1$} & [L6 $f / F b, p / 1 ; \mathrm{L} 12]$ \\
\hline & {$[p] . F b(1 p)$} & [S II: L13 $r / p ; \mathrm{L} 5 p / 1$ \\
\hline L15 & {$[p]: p . \equiv . p \equiv 1$} & [SII: D3 $p / 1, q / p ; \mathrm{L} 14]$ \\
\hline & $\equiv p . \equiv .1[$ S III: $]$ & $\mathrm{L} 15 p / q ; \mathrm{L} 15 p / q \equiv$ \\
\hline
\end{tabular}

At this point we can establish the following metatheorem:

$\mathbf{S} \mathbf{V}$ If we have in our system two theses of types

$F(0)$

$F(1)$

which are substitutions of some meaningful expression

$$
\text { [p] . } F(p)
$$

with the expressions ' 0 ' and ' 1 ' replacing the variable ' $p$ ', then we can add this latter expression to the system as a thesis in the following way:
a) $\quad F(0)$
b) $\quad F(1)$
c) $[p q] \therefore F(p) . \equiv q \equiv q: \equiv . G(q p)$
ঠ) $[p]: F(p) \equiv . G(0 p)$
e) $\quad G(00)$

[Assumption]

[Assumption]

$[\alpha]$

[S IV: L15 $p / F(p) ; c q / 0]$ [b $p / 0 ; \mathfrak{a}]$ 
f) $\quad G(01)$

g) $G(00) . \equiv .1$

h) $\quad G(0 G(00))$

i) $[r]: G(0 r) \equiv .1$

f) $\quad[p] \cdot G(0 p)$

l) $\quad[p] . F(p)$

[o $p / 1 ; \mathfrak{b}]$ [L15 $p / G(00) ; e]$

[S IV: $\mathrm{g} ; \mathrm{f}]$ [L6 $f / G, p / 0 ; \mathfrak{h}]$ [S II: $\mathrm{i} r / p ; \mathrm{L} 5 p / 0$ ] [S II: $\mathfrak{d} ; \mathfrak{l}]$.

With the help of $\mathrm{S} \mathrm{V}$, we prove the following theorems:

$\mathbf{L 1 8}[p] \therefore p . \equiv . p \equiv 0: \equiv .0$

[S II: $\mathrm{L} 17 q / p, p / p \equiv 0 ; \mathrm{L} 5 p / p \equiv 0]$

L19 $0 . \equiv .1 \equiv 0: \equiv .0 \therefore 0$

[S III: L18 $p / 1 ; \mathrm{L} 17 q / 0, p / 1 \equiv 0$ ]

L20 $[p]:: p . \equiv . p \equiv 0: \equiv \therefore 0 . \equiv .1 \equiv 0: \equiv .0$

[S IV: L19; L18]

D5 $[p q] \because: p . \equiv .1 \equiv 0: \equiv . q \equiv 0 \therefore \equiv . q \equiv 0:: \equiv . F c(p q)$

L21 0 . . $1 \equiv 0: \equiv .1 \therefore$. $F c(00)$

[S IV: L15 $p / 0 . \equiv .1 \equiv 0$;

D5 $p / 0, q / 0]$

L22 $0 . \equiv .1 \equiv 0: \equiv . F_{c}(00)$

[S IV: L15 $p / 0 . \equiv .1 \equiv 0 ; \mathrm{L} 21]$

$\mathbf{L 2 3} \quad F c(00 . \equiv .1 \equiv 0)$

L24 $F_{c}\left(0 F_{c}(00)\right)$

[S III: L22; L23]

L25 $[r]: F_{C}(0 r) . \equiv .1$

L26 $F c(00)$

L27 0 . $\equiv .1 \equiv 0$

L28 $0 \equiv 1 . \equiv .1 \equiv 0$

L29 $1 \equiv 0 . \equiv .0 \equiv 1$

L30 $[p]: p \equiv 1 . \equiv .1 \equiv p$

L31 $[p]: p \equiv 0 . \equiv .0 \equiv p$

L32 $[p q]: p \equiv q . \equiv . q \equiv p$

L33 $[p q] \therefore \mathrm{q} \equiv p . \equiv .1: \equiv: q \equiv 1 . \equiv . p$

L34 [pqr] $\therefore q \equiv p . \equiv . r: \equiv: q \equiv r . \equiv . p$

L35 $[p q r] \therefore \mathrm{p} \equiv q . \equiv . r: \equiv: q \equiv r . \equiv$

L36 $[p q r] \therefore \mathrm{p} \equiv q \equiv . \equiv: \equiv: p . q \equiv r$

L37 $[p q] \therefore \mathrm{p} . \equiv: q . \equiv . p \equiv q$

L38 $[p q] \therefore \mathrm{p} . \equiv: q . \equiv . q \equiv p$

$\mathbf{L 3 9}[p q]: p . \equiv . F b(p q)$

[D5 $p / 0, q / 0 . \equiv .1 \equiv 0 ;$ L20 $p / 0 . \equiv .1 \equiv 0]$

[L6 $f / F c, p / 0 ;$ L24]

[S II: L25 $r / 0 ; \mathrm{L} 5 p / 0$ ]

[S II: L22; L26]

[S III: L15 p/0; L27]

[S I: L28]

[S V: L28; L5 $p / 1 \equiv 1]$

[S V: L5 $p / 1 ;$ L29]

[S V: L31; L30]

[S I: L16]

[S V: L17; L33]

[S IV: L32; L34]

$\mathbf{L 4 0}[p q r] \therefore \mathrm{p} . \equiv: F b(q r) . \equiv . q \equiv p$

L41 $[p q r] \therefore F b(p F b(p 0)) . \equiv: F b(q r) . \equiv . q \equiv p$

[S III: L39 $q / F b(p 0)$; L40]

$\mathbf{L 4 2}[p q] \therefore F b(p F b(p 0)) . \equiv:[r]: F b(q r) . \equiv q \equiv p$

[S IV: L32 $q / q \equiv r ; \mathrm{L35}]$ $[\mathrm{L} 36 r / p \equiv q ; \mathrm{L} 5 p / p \equiv q]$

[L36 $r / q \equiv p ; \mathrm{L} 32]$

[S IV: L38; D3]

$\mathbf{L 4 3}[f p] \because p . \equiv:: f(p f(p 0)) . \equiv[r]: f(p r) . \equiv . p \equiv p \therefore \equiv . p$

[L $41 ; \beta]$

$[\mathrm{L} 37, q / p, p / f(p f(p 0)) . \equiv:[r]: f(p r) . \equiv . p \equiv p ; \mathrm{L} 6]$

$\mathbf{L} 44[p] \because p . \equiv::[f]:: f(p f(p 0)) . \equiv:[r]: f(p r) . \equiv . p \equiv p \therefore \equiv . p$

$\mathbf{L 4 5}[p]:: p . \therefore[f] \therefore f(p f(p 0)) . \equiv:[r]: f(1 r) . \equiv 1 \equiv p$

$[\mathrm{L} 43 ; \beta]$

[S IV: L15; $A_{n} q / 1$ ]

L46 $[p] \because:[f] \therefore f(p f(p 0)) . \equiv:[r]: f(1 r) . \equiv .1 \equiv p \therefore \equiv::[f]::$ $f(p f(p 0)) . \equiv:[r] . f(1 r) . \equiv .1 \equiv p \therefore \equiv .1$

$[\mathrm{L} 15 p / f(p f(p 0)) . \equiv:[r]: f(1 r) . \equiv .1 \equiv p ; \beta]$ 
$\mathbf{L 4 7}[p] \because: p . \equiv::[f]:: f(p f(p 0)) . \equiv:[r]: f(1 r) . \equiv .1 \equiv p \therefore \equiv .1$

[S IV: L45; L46]

D6 $^{4}[p q]:: p . \equiv::[f]:: f(p f(p 0)) . \equiv:[r]: f(q r) . \equiv . q \equiv p \therefore \equiv . q$ $\because \equiv . p \supset q$

$\mathbf{L 4 8}[p] . p \supset p$

$\mathbf{L 4 9}[p] . p \supset 1$

[D6 $q / p ;$ L44]

$\mathbf{L 5 0}[p] .0 \supset p$

[D6 $q / 1 ;$ L47]

L51 $1 \supset 1 . \equiv .1$

[S V: L48 $p / 0 ;$ L49 $p / 0$ ]

$\mathbf{L 5 2} 1$. つ. 1 つ 1

[L15 $p / 1 \supset 1 ; \mathrm{L} 48 p / 1]$

L53 0 . . 1 . $10: \equiv: 1$. 0 . 1

[S IV: L51; L48 $p / 1$ ]

L54 $1 . \supset .1 \supset 0: \equiv \therefore$. $1 . \supset: 1 . \supset .0 \equiv 1$

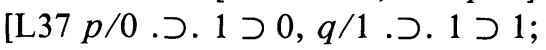

L50 $p / 1 \supset 0$; L52]

[S III: L15 $p / 0$;

L5 $p / 1$.つ. 1 ว 0]

$\mathbf{L 5 5}[p]:: p . \supset .1 \supset 0: \equiv .21 . \supset: 1 . \supset .0 \equiv p$

[S V: L53; L54]

L56 $1 . \supset \therefore 1$. $1.0 .1 \supset 0$

[L55 $p / 1 \supset 0 ; \mathrm{L} 48 p / 1 \supset 0$

At this point we prove the metatheorem:

$\mathbf{S ~ V I}{ }^{5}$ : If we have in the system corresponding theses

$A \supset B$

A

then we can add to the system the thesis

B.

a) $\quad A \supset B$

[Assumption]

b) $A$

[Assumption]

c) $\quad A . \equiv::[f]:: f(A f(A 0)) . \equiv:[r]: f(B r) . \equiv . B \equiv A \therefore \equiv . B$

ঠ) $[f]:: f(A f(A 0)) \equiv:[r]: f(B r) \equiv B \equiv A \stackrel{\therefore}{\equiv, B}$

e) $B \quad[\delta \mathrm{f} / F b ; \mathrm{L} 42 p / A, q / B]$

We then use this rule to prove

$\mathbf{L 5 7} 1 . \supset: 0.1 \supset 0$

L58 $0 . \equiv .1 \supset 0$

[S VI: L56; L5 $p / 0]$

[S VI: L57; L5 $p / 0$ ]

This completes the proof that the laws of implication can be derived from $A_{n}$ without using the rule of extensionality. Similar proofs may easily be constructed for $A_{m}, A_{o}, A_{p}$, and $A_{q}$ (see [8], p. 67 and [9], p. 122). On the other hand, it seems that the deductions from axiom $A_{l}$ and the proof of metatheorem $A 2^{6}$ require the use of theses of higher extensionality. Observe the crucial use of the rule for distributing quantifiers at L9, L42, L44, and L46; it is largely this rule and the unusual definition of implication at D6 which allow us to prove the laws of implication L48, L49, and L58.

It is well known that theses L32 and L36 are an adequate axiom system for the $E$-calculus ${ }^{7}$, and so replace the thesis A78 proved by Professor Sobociński. My research has concerned the axiom $A_{o}$, from which deductions are slightly shorter than those from $A_{n}{ }^{8}$; even a slight simplification of the known proof of A78 required 1,205 applications of the rule of inference of $\mathfrak{S}_{5}$, including 
definitions. The proof of L32 and L36 requires at most 583 applications of the rule, while the proof of the related system L34 and L59

L59

$$
\text { [pqr] } \therefore \mathrm{r} \equiv . \equiv \equiv \equiv: \equiv: r . \equiv . q \equiv p
$$

requires at most 568 applications of the rule. Hence the deductions outlined in this paper reduce to less than half its length the proof that $A_{0}$ is adequate for the $E$-calculus.

\section{NOTES}

1. The basic sources describing protothetic are [1], [2], and [3]. The articles [8], [9], and [10] are indispensable for serious study of the theory.

2. The proof given in L37 to L58 of this paper shows that derivations from this axiom need not rely on the theoretical considerations which led to its discovery. See [7], p. 19; [8], pp. 66-67; [10], p. 146, note 83; and especially [9], p. 122: "On the other hand I am unable to prove that $A_{n} \ldots$ is a single axiom of $\mathfrak{S}_{5}$ without the application of reasonings... in which point $\epsilon$ plays an essential role."

3. See [9], pp. 115-117 and 119-120. My formulation of these rules is slightly broader, as I refer to meaningful expressions instead of functors. My deductions diverge significantly from those in [9] from definition D4 onwards.

4. This unusual definition differs from any of those previously known, and from any of the related definitions of conjunction. For previous definitions see [1], p. 12, and [2], D3 on p. 93 and D4 on p. 107. For definitions of conjunction see [1], p. 13; [3], pp. 138, 141, and 147; [6], pp. 202-203; and the discussion in [10], pp. 134-144. Compare the proof of L58 with the theorem A1 in [10], pp. 134-139, to which it bears a close resemblance. I do not know how to shorten the present definition of implication and still carry out the proof of L58.

5. This rule is quite different from the S VI of [10], p. 132.

6. This axiom is found in [8], p. 66, and discussed in [9], pp. 123-124. The metatheorem appears in [10], pp. 139-144.

7. See [4], p. 91. Initial deductions from a closely related axiom system are given in [10], p. 314.

8. For example, the thesis L5 can be proved from $A_{o}$ in only 44 applications of the rule, but its proof from $A_{n}$ appears to require at least (and certainly at most) 48 applications. Even the initial deductions proving L32 and L36 from $A_{o}$ would require about 100 pages of print, so that I cannot see any possibility of publishing them.

\section{REFERENCES}

[1] Leśniewski, Stanisław, "Grundzüge eines neuen Systems der Grundlagen der Mathematik," Fundamenta Mathematicae, vol. 14 (1929), pp. 1-81.

[2] Leśniewski, Stanisław, "Grundzüge eines neuen Systems der Grundlagen der Mathematik (Fortsetzung)," Collectanea Logica, vol. 1 (1939), pp. 61-144. 
[3] Leśniewski, Stanisław, "Einleitende Bemerkungen zur Fortsetzung meiner Mitteilung u. d. T. Grundzüge eines neuen Systems der Grundlagen der Mathematik," Collectanea Logica, vol. 1 (1939), pp. 1-60. All page numbers cited are from the English translation in [5].

[4] Łukasiewicz, Jan, “Der Äquivalenzenkalkül,” Collectanea Logica, vol. 1 (1939), pp. 145-169. The citation refers to the pages of the English translation in [5].

[5] McCall, Storrs, ed., Polish Logic, 1920-1939, Clarendon Press, Oxford, 1967.

[6] Sobociński, Bolesław, "Z badań nad prototetykạ,” Collectanea Logica, vol. 1 (1939), pp. 171-176. The citation refers to the pages of the English translation in [5]. An earlier translation appears in Cahiers de l'Institut d'Études Polonaises en Belgique, no. 5 (1939), pp. 29-39.

[7] Sobociński, Bolesław, " $Z$ badań nad aksjomatykạ prototetyki Stanisława Leśniewskiego," Rocznik Polskiego Towarzystwa Naukowego na Obczyźnie, vol. 4 (1953-1954), pp. 18-20.

[8] Sobociński, Bolesław, "On the single axioms of protothetic," Notre Dame Journal of Formal Logic, vol. I (1960), pp. 52-73.

[9] Sobociński, Bolesław, "On the single axioms of protothetic," Notre Dame Journal of Formal Logic, vol. II (1961), pp. 111-126.

[10] Sobociński, Bolesław, "On the single axioms of protothetic," Notre Dame Journal of Formal Logic, vol. II (1961), pp. 129-148. The continuation of this article has not yet appeared.

[11] Wajsberg, Mordchaj, "Metalogische beiträge," Wiadomości Matematyczne, vol. 43 (1937), pp. 1-38. The citation refers to the page in the English translation in [5].

Department of Philosophy

University of Manchester

Manchester M13 9PL

England 
